\title{
Eficácia da associação entre os herbicidas clomazone e hexazinona no controle de plantas daninhas em cana-de-açúcar
}

\author{
Efficacy of clomazone and hexazinona association over weeds control in sugarcane
}

\author{
Caio Antonio Carbonari ${ }^{1}$, Edivaldo Domingues Velini ${ }^{2}$, Eduardo Negrisoli ${ }^{3}$, \\ Marcelo Rocha Corrêa ${ }^{3}$, Caio Vitagliano Santi Rossi ${ }^{4}$
}

\begin{abstract}
Resumo - O objetivo deste trabalho foi avaliar a eficácia da associação entre os herbicidas clomazone+hexazinona, aplicados em período de seca e em diferentes doses, sobre o solo e sobre a palha de cana-de-açúcar, no controle de plantas daninhas. O experimento foi instalado em 22 de agosto de 2007, em área pertencente à Fazenda Córrego do Campo, no município de Santa Maria da Serra/SP. As parcelas experimentais foram constituídas de cinco linhas de cana-de-açúcar espaçadas de 1,5 m, com $6 \mathrm{~m}$ de comprimento. Em todas as parcelas foram semeadas as espécies Brachiaria decumbens, Euphorbia heterophylla, Ipomoea grandifolia, Ipomoea nil, Ipomoea hederifolia, Ipomoea quamoclit e Merremia cissoides. Os tratamentos testados foram clomazone + hexazinona nas respectivas doses de $720+180 ; 800+200 ; 880+220$ e $1000+250 \mathrm{~g} \mathrm{ha}^{-1}$ e imazapic isolado a $147 \mathrm{~g} \mathrm{ha}^{-1}$, aplicados sobre o solo descoberto e sobre a palha de cana-deaçúcar e testemunhas sem aplicação de herbicidas, com e sem palha. Os tratamentos testados proporcionaram bons níveis de controle das espécies de plantas daninhas avaliadas, principalmente no período até 119 dias após a aplicação (DAA). Aos 153 DAA foram observados bons níveis de controle para $M$. cissoides, E. heterophylla, I. nil e B. decumbens para a associação de clomazone + hexazinona. Para I. quamoclit somente clomazone + hexazinona nas maiores doses, na presença e ausência de palha e o imazapic aplicado sobre a palha promoveram níveis satisfatórios de controle. Para I. hederifolia, aos 153 DAA, nenhuma das doses da associação de clomazone + hexazinona promoveram níveis satisfatórios de controle e o imazapic aplicado sobre a palha promoveu um controle efetivo desta espécie e para I. grandifolia somente o imazapic e clomazone + hexazinona na maior dose, ambos sobre a palha promoveram bons níveis de controle.
\end{abstract}

Palavras-chave: Déficit hídrico, controle químico, palha, Saccharum spp.

\footnotetext{
Abstract - The aim of this study was to evaluate the association between the herbicides clomazone + hexazinone applied during a dry period and at different doses, on soil and sugarcane mulch, in the weed control. The experiment was applied in August 22, 2007 in Santa Maria, São Paulo, Brazil. The experimental plots were constituted of five sugarcane lines spaced in $1,5 \mathrm{~m}$,

${ }^{1}$ Eng. Agr. Dr., Depto. Produção Vegetal, FCA/Unesp, Fazenda Experimental Lageado s/n, Caixa Postal 237, 18603 970, Botucatu-SP. e-mail: carbonari@fca.unesp.br;

${ }^{2}$ Professor Livre-docente Depto. Produção Vegetal, FCA/Unesp, Botucatu-SP;

${ }^{3}$ Eng.Agr. Dr., Depto.Produção Vegetal, FCA/Unesp, Botucatu-SP;

${ }^{4}$ Eng.Agr. Dr., Uberlândia-MG.
} 
with $6 \mathrm{~m}$ of length. In the plots were sown the weeds Brachiaria decumbens, Euphorbia heterophylla, Ipomoea grandifolia, Ipomoea nil, Ipomoea hederifolia, Ipomoea quamoclit e Merremia cissoides. The treatments were the herbicides clomazone + hexazinona at doses $720+$ $180 ; 800+200 ; 880+220$ e $1000+250 \mathrm{~g} \mathrm{ha}^{-1}$ and imazapic at $147 \mathrm{~g} \mathrm{ha}^{-1}$, applied over the soil and sugarcane mulch. Two herbicide untreated were also used as check, being one with and other without sugarcane mulch. The treatments promoted an efficacy control of weeds species evaluated, especially until 119 days after application (DAA). At 153 DAA were observed good control for $M$. cissoides, E. heterophylla, I. nil and B. decumbens for the association of clomazone + hexazinone. For I. quamoclit clomazone + hexazinone only at higher doses in the presence and absence of mulch and imazapic applied over the mulch promoted satisfactory levels of control. For I. hederifolia, to the 153 DAA, the combination of clomazone + hexazinone promoted unsatisfactory levels of control and imazapic applied on the straw promoted effective control of this species and I. grandifolia only imazapic and clomazone + hexazinone at the highest dose, both over the mulch promoted good control.

Key-words: Chemical control, mulch, water deficit, Saccharum spp.

\section{Introdução}

Na cultura da cana-de-açúcar, as plantas daninhas interferem no plantio e nas soqueiras e pelo fato do plantio da cultura ocorrer em períodos bem distintos, dependendo da região, as condições climáticas ocorrentes no período é que determinam as espécies daninhas predominantes e o período de interferência com a cultura (Victoria Filho e Christoffoleti, 2004).

Na cultura da cana-de-açúcar, a aplicação de herbicidas nos meses de maior restrição hídrica (maio a agosto) apresenta grande importância, pois neste período ocorre a colheita de grande parte da área plantada. $\mathrm{O}$ uso de herbicidas em época seca é uma estratégia de manejo bastante aplicada às grandes extensões de área, pois proporciona logística mais adequada e melhor aproveitamento da estrutura de aplicação. O planejamento da aplicação em função da área colhida pode proporcionar bons níveis de controle, desde que utilizados os produtos com as características adequadas a esta época de aplicação.

As características físico-químicas que contribuem para a manutenção da eficiência dos herbicidas no solo nos períodos de seca são a baixa volatilidade, a não fotodegradação, alta solubilidade, baixa adsorção aos colóides do solo e degradação principalmente via microbiana, já que em condição de solos secos, os microrganismos permanecem em repouso e tornam-se inativos (Guimarães, 1987). Assim, herbicidas com propriedades físico-químicas diferentes apresentam comportamentos distintos quando aplicados em condições de seca (Monquero et al., 2008). Segundo Christoffoleti e Lópes-Ovejero (2005), as características que permitem aos herbicidas serem aplicados em períodos secos sem perda de eficácia, ou no período chuvoso sem haver lixiviação devem ser criteriosamente observadas na seleção dos herbicidas mais adequados para cada situação.

Além disso, quando um herbicida é aplicado sobre a palhada, é interceptado pela superfície da palha e torna-se vulnerável à degradação causada pela volatilização e/ou fotodecomposição, até ser lixiviado para o solo (Locke e Bryson, 1997). Lamoreaux et al. (1993) ressaltam que a lixiviação de herbicidas da palha para o solo é dependente da capacidade desses resíduos em cobrir o solo e reter os herbicidas, da solubilidade do produto aplicado e do período em que a área permanece 
sem chuva após a aplicação do produto. No entanto, a partir do momento em que esses herbicidas passam pela palha e atingem o solo, apresentam maior distribuição e persistência, devido às características proporcionadas pela própria cobertura e pela amenização dos processos de perdas como, por exemplo, a fotodegradação (Jones et al., 1990; Sorenson et al., 1991; Maciel e Velini, 2005).

O objetivo deste trabalho foi avaliar a eficácia da associação entre os herbicidas clomazone+hexazinona, aplicados em período de seca e em diferentes doses sobre o solo e sobre a palha de cana-de-açúcar, no controle de algumas espécies de plantas daninhas.

\section{Material e métodos}

O experimento foi instalado em $22 \mathrm{de}$ agosto de 2007, durante o período de estiagem, em uma área de produção de cana-de-açúcar na Fazenda Córrego do Campo, no município de Santa Maria da Serra/SP. A análise do solo local foi realizada, de 0 a $10 \mathrm{~cm}$ de profundidade, revelando textura média, com $20 \%$ de argila, $4 \%$ de silte e $76 \%$ de areia, $\mathrm{pH}$ de 6,0 e 2,0 $\mathrm{g} \mathrm{dm}^{3}$ de matéria orgânica. A cultivar utilizada no experimento foi a RB 84 5210 , em seu $3^{\circ}$ corte $\mathrm{e}$ as parcelas experimentais apresentaram dimensões de 5 linhas de plantio, espaçadas de $1,5 \mathrm{~m}$ por $6 \mathrm{~m}$ de comprimento. A palha presente na área foi totalmente removida e acondicionada em sacos plásticos para permitir tratamentos sem palha e padronizar a quantidade de palha nos tratamentos com palha.

Nas duas entrelinhas centrais de cada parcela foram semeadas as plantas daninhas, em áreas de $0,5 \mathrm{~m}^{2}$ para cada espécie, sendo as sementes incorporadas de 0 a $8 \mathrm{~cm}$ de profundidade, para garantir a germinação no perfil do solo. A quantidade de sementes foi previamente avaliada em laboratório, por testes de germinação, para a obtenção de 100 plantas emergidas de cada espécie, em cada parcela, resultando em elevada população de plantas. O delineamento experimental utilizado foi o de blocos casualizados, com quatro repetições. As espécies de plantas daninhas semeadas e avaliadas foram B. decumbens, E. heterophylla, I. grandifolia, I. nil, I. hederifolia, I. quamoclit e $M$. cissoides.

Os tratamentos testados foram clomazone + hexazinona (Ranger) nas respectivas doses de $720+180 ; 800+200 ; 880+220$ e $1000+250$ $\mathrm{g} \mathrm{ha}^{-1} \mathrm{e}$ imazapic a $147 \mathrm{~g} \mathrm{ha}^{-1}$, aplicados sobre o solo e sobre a palha de cana-de-açúcar. Além disso, mantiveram-se testemunhas sem aplicação de herbicidas, com e sem palha da cultura. Nas parcelas com aplicação sobre a palha, realizou-se a cobertura do solo, com a palha retirada da área anteriormente, a qual foi pesada estimando-se a quantidade de $12 \mathrm{t} \mathrm{ha}^{-1}$.

A aplicação dos herbicidas foi realizada em pré-emergência das plantas daninhas e da cultura utilizando-se pulverizador costal pressurizado com $\mathrm{CO}_{2}$, munido com barra equipada com quatro pontas de pulverização, modelo DG110.02vs, espaçadas $0,5 \mathrm{~m}$ entre si, regulado com pressão constante de $2,0 \mathrm{kgf} \mathrm{cm}^{-}$ ${ }^{2}$, a vazão de $200 \mathrm{~L} \mathrm{ha}^{-1}$ As condições atmosféricas no momento das aplicações dos herbicidas foram: temperatura de $23^{\circ} \mathrm{C}$, umidade relativa do ar de $45 \%$, e ventos com velocidade de 3,5 a 9,0 $\mathrm{km} \mathrm{h}^{-1}$. Na Figura 1 estão apresentados os índices pluviométricos e temperatura do ar durante o período de condução do experimento. 


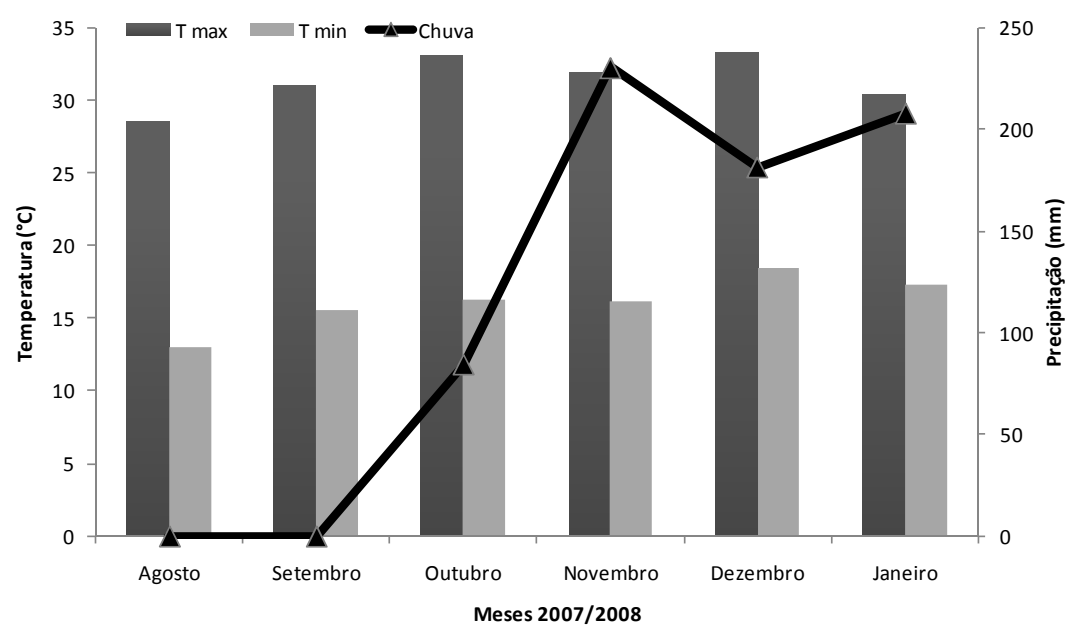

Figura 1. Índices pluviométricos e temperatura do ar na região durante o período do experimento. Santa Maria da Serra/SP, 2007.

Avaliações visuais de eficácia dos herbicidas no controle das plantas daninhas foram realizadas, segundo escala percentual, na qual "zero" representou ausência de controle e "100", a morte total da planta daninha, conforme Sociedade Brasileira da Ciência das Plantas Daninhas (1995). As avaliações foram realizadas aos 23, 63, 91, 119 e 153 dias após a aplicação dos herbicidas (DAA). Os resultados obtidos foram submetidos à análise de variância pelo teste $\mathrm{F}$, e as médias comparadas pelo teste de Tukey, a 5\% de probabilidade.

\section{Resultados e discussão}

De acordo com os resultados de controle das plantas daninhas aos 23 DAA (Tabela 1), verificou-se eficácia de controle da associação entre os herbicidas clomazone + hexazinona para a maioria das plantas daninhas testadas. Para as espécies $B$. decumbens, $I$. quamoclit, I. grandifolia, I. nil e M. cissoides o controle promovido pelo herbicida imazapic, aplicado sobre o solo, foi inferior às aplicações da mistura de clomazone + hexazinona. Azania et al. (2004) constataram que uma camada de palha de $15 \mathrm{t} \mathrm{ha}^{-1}$ possui potencial para reter $\mathrm{o}$ herbicida imazapic, especialmente sob períodos de pouca precipitação ou irrigação. No entanto, Cavenaghi et al. (2006) observaram que a ocorrência de $20 \mathrm{~mm}$ de chuva foi suficiente para a lixiviação de $96 \%$ do imazapic depositado sobre $10 \mathrm{t} \mathrm{ha}^{-1}$ de palha para o solo.

Quanto ao controle dessas espécies pelo herbicida imazapic, verificou-se que o melhor controle foi observado para a aplicação sobre a palha, demonstrando que tal condição não caracterizou barreira física para que o herbicida atingisse o solo, e auxiliou na supressão das plantas daninhas. Medeiros (2001) avaliou a eficácia do herbicida imazapic no controle de tiririca (Cyperus rotundus) em presença de palha de cana-de-açúcar e observou que este herbicida apresentou altos níveis de transposição através da palha de cana, independentemente da quantidade de água (10 ou $20 \mathrm{~mm}$ ) aplicada após a pulverização do herbicida.

Para I. hederifolia, foram observados excelentes níveis de controle, independente do tratamento testado e para $E$. heterophylla não houve diferença significativa entre os tratamentos. 
Tabela 1. Porcentagem de controle das plantas daninhas após a aplicação dos herbicidas, aos 23DAA. Santa Maria da Serra/SP, 2007.

\begin{tabular}{|c|c|c|c|c|c|c|c|}
\hline Tratamentos & $\begin{array}{l}\text { Brachiaria } \\
\text { decumbens }\end{array}$ & $\begin{array}{c}\text { Ipomoea } \\
\text { grandifolia }\end{array}$ & $\begin{array}{l}\text { Ipomoea } \\
\text { quamoclit }\end{array}$ & $\begin{array}{c}\text { Ipomoea } \\
\mathrm{Nil}\end{array}$ & $\begin{array}{c}\text { Ipomoea } \\
\text { hederifolia }\end{array}$ & $\begin{array}{c}\text { Euphorbia } \\
\text { heterophylla }\end{array}$ & $\begin{array}{l}\text { Merremia } \\
\text { cissoides }\end{array}$ \\
\hline clomazone + hexazinona $\left(720+180 \mathrm{~g} \mathrm{ha}^{-1}\right)$ sobre o solo & $98,7 \mathrm{a}$ & $99,5 \mathrm{ab}$ & $98,5 \mathrm{a}$ & $100,0 \mathrm{a}$ & 100,0 & 94,7 & $98,0 \mathrm{ab}$ \\
\hline clomazone + hexazinona $\left(720+180 \mathrm{~g} \mathrm{ha}^{-1}\right)$ sobre a palha & $100,0 \mathrm{a}$ & $100,0 \mathrm{a}$ & $100,0 \mathrm{a}$ & $100,0 \mathrm{a}$ & 100,0 & 65,2 & $97,5 \mathrm{ab}$ \\
\hline clomazone + hexazinona $\left(800+200 \mathrm{~g} \mathrm{ha}^{-1}\right)$ sobre o solo & 98,7 a & $100,0 \mathrm{a}$ & 94,7 a & $100,0 \mathrm{a}$ & 100,0 & 99,7 & $99,2 \mathrm{ab}$ \\
\hline clomazone + hexazinona $\left(800+200 \mathrm{~g} \mathrm{ha}^{-1}\right)$ sobre a palha & $100,0 \mathrm{a}$ & $99,5 \mathrm{ab}$ & $100,0 \mathrm{a}$ & 98,2 a & 100,0 & 95,0 & $99,5 \mathrm{ab}$ \\
\hline clomazone + hexazinona $\left(880+220 \mathrm{~g} \mathrm{ha}^{-1}\right)$ sobre o solo & 99,7 a & $100,0 \mathrm{a}$ & 99,0 a & $91,2 \mathrm{ab}$ & 100,0 & 87,5 & $99,5 \mathrm{ab}$ \\
\hline clomazone + hexazinona $\left(880+220 \mathrm{~g} \mathrm{ha}^{-1}\right)$ sobre a palha & $97,0 \mathrm{a}$ & $100,0 \mathrm{a}$ & $100,0 \mathrm{a}$ & $93,0 \mathrm{ab}$ & 100,0 & 67,0 & $79,2 \mathrm{ab}$ \\
\hline clomazone + hexazinona $\left(1000+250 \mathrm{~g} \mathrm{ha}^{-1}\right)$ sobre o solo & $100,0 \mathrm{a}$ & $100,0 \mathrm{a}$ & $100,0 \mathrm{a}$ & 99,2 a & 100,0 & 99,0 & $99,7 \mathrm{ab}$ \\
\hline clomazone + hexazinona $\left(1000+250 \mathrm{~g} \mathrm{ha}^{-1}\right)$ sobre a palha & $100,0 \mathrm{a}$ & $100,0 \mathrm{a}$ & $100,0 \mathrm{a}$ & $100,0 \mathrm{a}$ & 100,0 & 92,2 & $100,0 \mathrm{a}$ \\
\hline imazapic $\left(147 \mathrm{~g} \mathrm{ha}^{-1}\right)$ sobre o solo & $80,0 \mathrm{~b}$ & $66,2 \mathrm{c}$ & $71,2 \mathrm{~b}$ & $72,5 \mathrm{~b}$ & 81,0 & 55,0 & $66,2 \mathrm{~b}$ \\
\hline imazapic $\left(147 \mathrm{~g} \mathrm{ha}^{-1}\right)$ sobre a palha & 99,7 a & $82,5 \mathrm{bc}$ & $100,0 \mathrm{a}$ & $91,0 \mathrm{ab}$ & 100,0 & 78,5 & $68,7 \mathrm{ab}$ \\
\hline F tratamento & $9,40 * *$ & $\overline{8}, \overline{4} \overline{5}^{*} \bar{*}-$ & $\overline{7}, \overline{2} 2^{* *}-$ & $-\overline{3}, \overline{3} \overline{7} \bar{*} *-$ & $\overline{1}, \overline{8} \overline{2}^{\mathrm{ns}}$ & $\overline{1,5} \overline{5}^{\text {ns }}$ & $3,22 * *$ \\
\hline $\mathrm{CV}(\%)$ & 4,15 & 8,29 & 6,93 & 9.92 & 9,08 & 30,73 & 16,91 \\
\hline DMS & 8,84 & 17,20 & 14,61 & 20,53 & 19,51 & 56,13 & 33,62 \\
\hline
\end{tabular}

Médias seguidas por mesma letra, na coluna, não diferem entre si pelo teste de Tukey a $5 \%$ de probabilidade.

* - significativo a $5 \%$; ** - significativo a $1 \%$; ${ }^{\text {ns }}$-Não significativo

Aos 63 DAA e 91 DAA (Tabelas 2 e 3) foram observados excelentes níveis de controle (acima de 90\%) para todas as espécies de plantas daninhas, para os herbicidas, doses e condições avaliadas.

Tabela 2. Porcentagem de controle das plantas daninhas após a aplicação dos herbicidas, aos 63 DAA. Santa Maria da Serra/SP, 2007.

\begin{tabular}{|c|c|c|c|c|c|c|c|}
\hline Tratamentos & $\begin{array}{l}\text { Brachiaria } \\
\text { decumbens }\end{array}$ & $\begin{array}{c}\text { Ipomoea } \\
\text { grandifolia }\end{array}$ & $\begin{array}{l}\text { Ipomoea } \\
\text { quamoclit }\end{array}$ & $\begin{array}{c}\text { Ipomoea } \\
\text { nil }\end{array}$ & $\begin{array}{c}\text { Ipomoea } \\
\text { hederifolia }\end{array}$ & $\begin{array}{c}\text { Euphorbia } \\
\text { heterophylla }\end{array}$ & $\begin{array}{l}\text { Merremia } \\
\text { cissoides }\end{array}$ \\
\hline clomazone + hexazinona $\left(720+180 \mathrm{~g} \mathrm{ha}^{-1}\right)$ sobre o solo & 100,0 & 100,0 & 100,0 & 100,0 & 100,0 & 98,7 & 100,0 \\
\hline clomazone + hexazinona $\left(720+180 \mathrm{~g} \mathrm{ha}^{-1}\right)$ sobre a palha & 100,0 & 100,0 & 100,0 & 100,0 & 100,0 & 94,7 & 100,0 \\
\hline clomazone + hexazinona $\left(800+200 \mathrm{~g} \mathrm{ha}^{-1}\right)$ sobre o solo & 100,0 & 100,0 & 100,0 & 100,0 & 100,0 & 100,0 & 100,0 \\
\hline clomazone + hexazinona $\left(800+200 \mathrm{~g} \mathrm{ha}^{-1}\right)$ sobre a palha & 100,0 & 100,0 & 100,0 & 100,0 & 100,0 & 100,0 & 100,0 \\
\hline clomazone +hexazinona $\left(880+220 \mathrm{~g} \mathrm{ha}^{-1}\right)$ sobre o solo & 100,0 & 100,0 & 100,0 & 100,0 & 100,0 & 100,0 & 100,0 \\
\hline clomazone + hexazinona $\left(880+220 \mathrm{~g} \mathrm{ha}^{-1}\right)$ sobre a palha & 95,0 & 100,0 & 100,0 & 100,0 & 100,0 & 100,0 & 100,0 \\
\hline clomazone + hexazinona $\left(1000+250 \mathrm{~g} \mathrm{ha}^{-1}\right)$ sobre o solo & 100,0 & 100,0 & 100,0 & 100,0 & 100,0 & 100,0 & 100,0 \\
\hline clomazone + hexazinona $\left(1000+250 \mathrm{~g} \mathrm{ha}^{-1}\right)$ sobre a palha & 100,0 & 100,0 & 100,0 & 100,0 & 100,0 & 100,0 & 100,0 \\
\hline imazapic $\left(147 \mathrm{~g} \mathrm{ha}^{-1}\right)$ sobre o solo & 100,0 & 100,0 & 100,0 & 100,0 & 100,0 & 100,0 & 100,0 \\
\hline imazapic $\left(147 \mathrm{~g} \mathrm{ha}^{-1}\right)$ sobre a palha & 100,0 & 100,0 & 100,0 & 100,0 & 100,0 & 100,0 & 100,0 \\
\hline F tratamento & $1,00^{n 5}$ & - & - & - & $\overline{-}$ & $\overline{1}, \overline{14^{n s}}$ & - \\
\hline $\mathrm{CV}(\%)$ & 3,18 & - & - & - & - & 3,14 & - \\
\hline DMS & 6,92 & - & - & - & - & 6,83 & - \\
\hline
\end{tabular}

Médias seguidas por mesma letra, na coluna, não diferem entre si pelo teste de Tukey a $5 \%$ de probabilidade. ${ }^{\text {ns }}$ - Não significativo 
A ocorrência de chuvas, após a primeira avaliação (Figura 1) possivelmente proporcionou a lixiviação dos produtos da palha para o solo, ocasionando altos níveis de controle das espécies avaliadas. Estes resultados corroboram com Correa (2006) que observou para diuron + hexazinona, que chuvas superiores a $20 \mathrm{~mm}$ são capazes de

Tabela 3. Porcentagem de controle das plantas daninhas após a aplicação dos herbicidas, aos 91DAA. Santa Maria da Serra/SP, 2007.

\begin{tabular}{|c|c|c|c|c|c|c|c|}
\hline Tratamentos & $\begin{array}{l}\text { Brachiaria } \\
\text { decumbens }\end{array}$ & $\begin{array}{c}\text { Ipomoea } \\
\text { grandifolia }\end{array}$ & $\begin{array}{l}\text { Ipomoea } \\
\text { quamoclit }\end{array}$ & $\begin{array}{c}\text { Ipomoea } \\
\text { nil }\end{array}$ & $\begin{array}{c}\text { Ipomoea } \\
\text { hederifolia }\end{array}$ & $\begin{array}{c}\text { Euphorbia } \\
\text { heterophylla }\end{array}$ & $\begin{array}{l}\text { Merremia } \\
\text { cissoides }\end{array}$ \\
\hline clomazone + hexazinona $\left(720+180 \mathrm{~g} \mathrm{ha}^{-1}\right)$ sobre o solo & $100,0 \mathrm{a}$ & 100,0 & 100,0 & 100,0 & 90,0 & 99,5 & 100,0 \\
\hline clomazone + hexazinona $\left(720+180 \mathrm{~g} \mathrm{ha}^{-1}\right)$ sobre a palha & $100,0 \mathrm{a}$ & 100,0 & 100,0 & 99,7 & 92,5 & 99,5 & 100,0 \\
\hline clomazone + hexazinona $\left(800+200 \mathrm{~g} \mathrm{ha}^{-1}\right)$ sobre o solo & $100,0 \mathrm{a}$ & 100,0 & 100,0 & 100,0 & 100,0 & 100,0 & 100,0 \\
\hline clomazone + hexazinona $\left(800+200 \mathrm{~g} \mathrm{ha}^{-1}\right)$ sobre a palha & $100,0 \mathrm{a}$ & 100,0 & 80,0 & 99,7 & 100,0 & 100,0 & 100,0 \\
\hline clomazone + hexazinona $\left(880+220 \mathrm{~g} \mathrm{ha}^{-1}\right)$ sobre o solo & $100,0 \mathrm{a}$ & 100,0 & 100,0 & 100,0 & 100,0 & 99,7 & 100,0 \\
\hline clomazone + hexazinona $\left(880+220 \mathrm{~g} \mathrm{ha}^{-1}\right)$ sobre a palha & $100,0 \mathrm{a}$ & 100,0 & 100,0 & 99,7 & 100,0 & 100,0 & 100,0 \\
\hline clomazone + hexazinona $\left(1000+250 \mathrm{~g} \mathrm{ha}^{-1}\right)$ sobre o solo & 98,7 a & 97,5 & 97,5 & 97,5 & 100,0 & 75,0 & 100,0 \\
\hline clomazone + hexazinona $\left(1000+250 \mathrm{~g} \mathrm{ha}^{-1}\right)$ sobre a palha & $100,0 \mathrm{a}$ & 100,0 & 100,0 & 100,0 & 100,0 & 96,2 & 100,0 \\
\hline imazapic $\left(147 \mathrm{~g} \mathrm{ha}^{-1}\right)$ sobre o solo & $93,7 \mathrm{~b}$ & 99,7 & 100,0 & 99,7 & 99,5 & 100,0 & 100,0 \\
\hline imazapic $\left(147 \mathrm{~g} \mathrm{ha}^{-1}\right)$ sobre a palha & $100,0 \mathrm{a}$ & 100,0 & 100,0 & 100,0 & 100,0 & 100,0 & 100,0 \\
\hline F tratamento & $\overline{8}, \overline{4} 1^{* *} \cdot$ & $\overline{0}, \overline{9} \overline{8}^{n-}$ & $\overline{0}, \overline{9} 7^{\mathrm{ns}}$ & $0,90^{\text {ns }}$ & $0, \overline{8} \overline{8}^{n-}$ & $0, \overline{9} 5^{n-}$ & - \\
\hline $\mathrm{CV}(\%)$ & 1,37 & 1,59 & 13,04 & 1,62 & 8,06 & 16,49 & - \\
\hline DMS & 2,98 & 3,48 & 27,92 & 3,53 & 17,33 & 35,03 & - \\
\hline
\end{tabular}

Médias seguidas por mesma letra, na coluna, não diferem entre si pelo teste de Tukey a $5 \%$ de probabilidade.

* - significativo a $5 \% ; * *$ - significativo a $1 \%$; ns - Não significativo

Aos 119 DAA (Tabela 4), também se observou bons níveis de controle (acima de $80 \%$ ) para os tratamentos e espécies testadas, exceto, para I. grandifolia no tratamento com o herbicida imazapic sobre o solo e para as espécies I. quamoclit e I. nil com aplicação do clomazone + hexazinona na dose de $720+180$ $\mathrm{g} \mathrm{ha}{ }^{-1}$ aplicado sobre a palha. Para $I$. hederifolia o melhor resultado de controle foi observado para o herbicida imazapic aplicado na presença de palha e para as dose de clomazone + hexazinona superiores a $800+$ $200 \mathrm{~g} \mathrm{ha}^{-1}$ com ou sem palha.

$\mathrm{Na}$ Tabela 5, estão apresentados os resultados observados aos 153 DAA, ocasião em que se verificaram bons níveis de controle lixiviar mais de $98 \%$ dos herbicidas, com 5 a $20 \mathrm{t} \mathrm{ha}^{-1}$ de palha de cana-de-açúcar no solo. Entretanto, Mills et al. (1989) avaliaram a dinâmica de clomazone em cobertura vegetal na cultura do trigo e observaram que mais de $40 \%$ do produto não atingiu o solo, sendo retido pela palha e/ou volatilizado. 
Tabela 4. Porcentagem de controle das plantas daninhas após a aplicação dos herbicidas, aos 119DAA. Santa Maria da Serra/SP, 2007.

\begin{tabular}{|c|c|c|c|c|c|c|c|}
\hline Tratamentos & $\begin{array}{l}\text { Brachiaria } \\
\text { decumbens }\end{array}$ & $\begin{array}{c}\text { Ipomoea } \\
\text { grandifolia }\end{array}$ & $\begin{array}{l}\text { Ipomoea } \\
\text { quamoclit }\end{array}$ & $\begin{array}{c}\text { Ipomoea } \\
\text { nil }\end{array}$ & $\begin{array}{c}\text { Ipomoea } \\
\text { hederifolia }\end{array}$ & $\begin{array}{c}\text { Euphorbia } \\
\text { heterophylla }\end{array}$ & $\begin{array}{l}\text { Merremia } \\
\text { cissoides }\end{array}$ \\
\hline clomazone + hexazinona $\left(720+180 \mathrm{~g} \mathrm{ha}^{-1}\right)$ sobre o solo & $100,0 \mathrm{a}$ & 95,5 a & 93,0 & 80,0 & $79,0 \mathrm{~b}$ & 96,7 & 97,7 \\
\hline clomazone + hexazinona $\left(720+180 \mathrm{~g} \mathrm{ha}^{-1}\right)$ sobre a palha & $100,0 \mathrm{a}$ & 98,7 a & 77,5 & 78,7 & $82,5 \mathrm{a}$ & 93,7 & 97,2 \\
\hline clomazone + hexazinona $\left(800+200 \mathrm{~g} \mathrm{ha}^{-1}\right)$ sobre o solo & $100,0 \mathrm{a}$ & $95,5 \mathrm{a}$ & 98,7 & 81,7 & 97,2 a & 100,0 & 98,2 \\
\hline clomazone + hexazinona $\left(800+200 \mathrm{~g} \mathrm{ha}^{-1}\right)$ sobre a palha & $100,0 \mathrm{a}$ & 99,0 a & 100,0 & 85,0 & $100,0 \mathrm{a}$ & 98,5 & 100,0 \\
\hline clomazone + hexazinona $\left(880+220 \mathrm{~g} \mathrm{ha}^{-1}\right)$ sobre o solo & 99,7 a & 94,7 a & 96,7 & 81,2 & 97,7 a & 99,5 & 97,2 \\
\hline clomazone + hexazinona $\left(880+220 \mathrm{~g} \mathrm{ha}^{-1}\right)$ sobre a palha & $100,0 \mathrm{a}$ & $99,0 \mathrm{a}$ & 99,5 & 83,7 & $100,0 \mathrm{a}$ & 100,0 & 100,0 \\
\hline clomazone + hexazinona $\left(1000+250 \mathrm{~g} \mathrm{ha}^{-1}\right)$ sobre o solo & $100,0 \mathrm{a}$ & 98,0 a & 100,0 & 97,5 & $100,0 \mathrm{a}$ & 100,0 & 98,0 \\
\hline clomazone + hexazinona $\left(1000+250 \mathrm{~g} \mathrm{ha}^{-1}\right)$ sobre a palha & $100,0 \mathrm{a}$ & $98,5 \mathrm{a}$ & 100,0 & 94,2 & $100,0 \mathrm{a}$ & 93,2 & 99,2 \\
\hline imazapic $\left(147 \mathrm{~g} \mathrm{ha}^{-1}\right)$ sobre o solo & $80,7 \mathrm{~b}$ & $67,7 \mathrm{~b}$ & 99,2 & 90,7 & $100,0 \mathrm{a}$ & 100,0 & 99,5 \\
\hline imazapic $\left(147 \mathrm{~g} \mathrm{ha}^{-1}\right)$ sobre a palha & $100,0 \mathrm{a}$ & 95,0 a & 95,0 & 99,5 & $100,0 \mathrm{a}$ & 99,7 & 100,0 \\
\hline F tratamento & $3,96^{*-}$ & $4,94 * *$ & $0,86^{n 5}$ & $0, \overline{6} 3^{\text {ns }}$ & $2,6 \overline{6}^{* \bar{*}}$ & $1,84^{n-5}$ & $1,5 \overline{6}^{n-5}$ \\
\hline $\mathrm{CV}(\%)$ & 7,20 & 9,03 & 15,57 & 22,03 & 17,54 & 3,99 & 1,86 \\
\hline DMS & 15,59 & 18,61 & 32,73 & 42,11 & 26,74 & 8,58 & 4,01 \\
\hline
\end{tabular}

Médias seguidas por mesma letra, na coluna, não diferem entre si pelo teste de Tukey a $5 \%$ de probabilidade.

* - significativo a $5 \%$; ** - significativo a $1 \%$; ${ }^{\text {ns }}$ - Não significativo

Para B. decumbens foram observadas falhas no controle somente para o herbicida imazapic, na ausência e presença de palha e para M. cissoides, foram observados níveis de controle, (acima de 90\%) para todos os herbicidas testados, exceto para aplicação de clomazone + hexazinona na dose $720+180 \mathrm{~g}$ $\mathrm{ha}^{-1}$, aplicado sobre a palha.

Tabela 5. Porcentagem de controle das plantas daninhas após a aplicação dos herbicidas, aos 153DAA.Santa Maria da Serra/SP, 2007.

\begin{tabular}{|c|c|c|c|c|c|c|c|}
\hline Tratamentos & $\begin{array}{l}\text { Brachiaria } \\
\text { decumbens }\end{array}$ & $\begin{array}{c}\text { Ipomoea } \\
\text { grandifolia }\end{array}$ & $\begin{array}{l}\text { Ipomoea } \\
\text { quamoclit }\end{array}$ & $\begin{array}{c}\text { Ipomoea } \\
\text { nil }\end{array}$ & $\begin{array}{c}\text { Ipomoea } \\
\text { hederifolia }\end{array}$ & $\begin{array}{c}\text { Euphorbia } \\
\text { heterophylla }\end{array}$ & $\begin{array}{l}\text { Merremia } \\
\text { cissoides }\end{array}$ \\
\hline clomazone + hexazinona $\left(720+180 \mathrm{~g} \mathrm{ha}^{-1}\right)$ sobre o solo & $100,0 \mathrm{a}$ & $40,0 \mathrm{a}$ & $50,0 \mathrm{~b}$ & 92,7 & $26,2 \mathrm{bc}$ & 99,5 & 98,5 \\
\hline clomazone + hexazinona $\left(720+180 \mathrm{~g} \mathrm{ha}^{-1}\right)$ sobre a palha & 100,0 a & 63,0 a & $50,0 \mathrm{~b}$ & 96,5 & $46,2 \mathrm{abc}$ & 77,5 & 75,0 \\
\hline clomazone + hexazinona $\left(800+200 \mathrm{~g} \mathrm{ha}^{-1}\right)$ sobre o solo & $100,0 \mathrm{a}$ & 52,5 a & $25,0 \mathrm{~b}$ & 87,2 & $7,5 \mathrm{c}$ & 100,0 & 99,5 \\
\hline clomazone + hexazinona $\left(800+200 \mathrm{~g} \mathrm{ha}^{-1}\right)$ sobre a palha & $100,0 \mathrm{a}$ & 81,2 a & $75,0 \mathrm{~b}$ & 95,2 & $74,5 \mathrm{ab}$ & 75,0 & 99,5 \\
\hline clomazone + hexazinona $\left(880+220 \mathrm{~g} \mathrm{ha}^{-1}\right)$ sobre o solo & $100,0 \mathrm{a}$ & $32,2 \mathrm{~b}$ & $50,0 \mathrm{~b}$ & 85,0 & $8,7 \mathrm{c}$ & 97,5 & 94,2 \\
\hline clomazone + hexazinona $\left(880+220 \mathrm{~g} \mathrm{ha}^{-1}\right)$ sobre a palha & $95,0 \mathrm{a}$ & 72,7 a & $100,0 \mathrm{a}$ & 73,2 & $32,5 \mathrm{bc}$ & 96,0 & 91,5 \\
\hline clomazone + hexazinona $\left(1000+250 \mathrm{~g} \mathrm{ha}^{-1}\right)$ sobre o solo & 100,0 a & 61,5 a & $100,0 \mathrm{a}$ & 87,5 & $0,0 \mathrm{c}$ & 100,0 & 98,0 \\
\hline clomazone + hexazinona $\left(1000+250 \mathrm{~g} \mathrm{ha}^{-1}\right)$ sobre a palha & $100,0 \mathrm{a}$ & 91,2 a & $100,0 \mathrm{a}$ & 89,2 & $50,2 \mathrm{abc}$ & 81,0 & 97,7 \\
\hline imazapic $\left(147 \mathrm{~g} \mathrm{ha}^{-1}\right)$ sobre o solo & $10,0 \mathrm{~b}$ & 59,5 a & $75,0 \mathrm{~b}$ & 93,2 & $0,0 \mathrm{c}$ & 99,7 & 99,0 \\
\hline imazapic $\left(147 \mathrm{~g} \mathrm{ha}^{-1}\right)$ sobre a palha & $62,0 \mathrm{~b}$ & $87,0 \mathrm{a}$ & $100,0 \mathrm{a}$ & 96,7 & 93,7 a & 98,2 & 99,0 \\
\hline $\bar{F}$ tratamento & $\overline{7}, \overline{4} 2^{*} \bar{*}-$ & $\overline{1}, \overline{84 * *}$ & $1, \overline{3} * \bar{*} \cdot$ & $0, \overline{7} \overline{2}^{\text {ns }}$ & $\overline{7,22} * \bar{*}$ & $1,09^{n-5}$ & $0, \overline{8} 3^{n-}$ \\
\hline $\mathrm{CV}(\%)$ & 25,57 & 46,64 & 57,70 & 18,67 & 70,58 & 21,26 & 17,45 \\
\hline DMS & 27,43 & 66,50 & 23,62 & 36,66 & 11,99 & 43,04 & 36,39 \\
\hline
\end{tabular}

Médias seguidas por mesma letra, na coluna, não diferem entre si pelo teste de Tukey a $5 \%$ de probabilidade.

* - significativo a $5 \%$; ** - significativo a $1 \%$; ns - Não significativo 
Para algumas espécies foram observados baixos níveis de controle, ou seja, aos 153 DAA o residual do produto presente no solo não foi suficiente para promover o controle. Para I. quamoclit, somente imazapic em associação com a palha, o clomazone + hexazinona na dose de $880+220 \mathrm{~g} \mathrm{ha}^{-1}$ sobre a palha e o clomazone + hexazinona a $1000+$ $250 \mathrm{~g} \mathrm{ha}^{-1}$ na presença ou ausência de palha promoveram excelentes níveis de controle e Para I. hederifolia somente o imazapic com aplicação sobre a palha promoveu um excelente controle. Observou-se ainda neste período de avaliação, que o clomazone + hexazinona a $1000+250 \mathrm{~g} \mathrm{ha}^{-1}$ e o imazapic aplicado sobre a palha promoveram resultados satisfatórios de controle de I. grandifolia. Monquero et al (2008), verificaram que a mistura de diuron + hexazinona, apresentou efeito residual, maior que 90 dias, no controle de plantas daninhas para aplicações em condições de seca.

\section{Conclusões}

De maneira geral, os tratamentos testados proporcionaram bons níveis de controle das espécies de plantas daninhas avaliadas, principalmente no período até 119 DAA.

Aos 153 DAA foram observados bons níveis de controle para $M$. cissoides, $E$. heterophylla, I. nil e B. decumbens para a associação de clomazone + hexazinona. Para $I$. quamoclit somente clomazone + hexazinona nas maiores doses, na presença e ausência de palha e o imazapic aplicado sobre a palha promoveram níveis satisfatórios de controle.

Para I. hederifolia, aos 153 DDA, nenhuma dose da associação de clomazone + hexazinona promoveram níveis satisfatórios de controle e o imazapic aplicado sobre a palha promoveu um controle efetivo desta espécie e para I. grandifolia somente o imazapic e clomazone + hexazinona na maior dose, ambos sobre a palha promoveram bons níveis de controle.

\section{Referências}

AZANIA, C.A.M. et al. Seletividade do imazapic para duas cultivares de amendoim (Arachis hypogaea) cultivadas na ausência e na presença de palha de cana-de-açúcar. Planta Daninha, v. 22, n.1, p.145-150, 2004.

CAVENAGHI, A.L. et al. Dinâmica do herbicida imazapic aplicado sobre a palha de cana-de-açúcar. In: CONGRESSO BRASILEIRO DA CIÊNCIA DAS PLANTAS DANINHAS, 25., 2006, Brasília. Resumos... Brasília: SBCPD; UNB; Embrapa Cerrados, 2006. p. 360.

CHRISTOFFOLETI, J.C.; LÓPEZ-OVEJERO, R.F. Dinâmica dos herbicidas aplicados ao solo na cultura da cana-de-açúcar. São Paulo, 2005. 49 p.

CORRÊA, M.R. Dinâmica e eficácia da mistura formulada de diuron e hexazinane no sistema de produção de cana crua. 2006, 150p. Tese (Doutorado em Agronomia/Agricultura) - Faculdade de Ciências Agronômicas. Universidade Estadual Paulista, Botucatu, 2006.

GUIMARÃES, G.L. Impactos ecológicos do uso de herbicidas ao meio ambiente. Série Técnica IPEF, v.4, n.2, p.159-180, 1987.

JONES JR, R.E.; BANKS, P.A.; RADCLIFFE, D. E. Alachlor and metribuzin movement and dissipation in a soil profile as influenced by soil surface condition. Weed Science, v.38, n.2, p.589-597, 1990.

LAMOREAUX, R. J.; JAIN, R.; HESS, F. D. Efficacy of dimethenamid, metolachlor and encapsulated alachlor in soil covered with crop residue. In: BRIGHTON CROP PROTECTION CONFERENCE - XX. Weeds, v.3, p.1015-1220, 1993. 
LOCKE, M.A.; BRYSON, C.T. Herbicide-soil interaction in reduced tillage and plant residue management systems. Weed Science, v.45, n.2, p.307-320, 1997.

MACIEL, C.D.G; VELINI, E.D. Simulação do caminhamento da água da chuva e herbicidas em palhadas utilizadas me sistemas de plantio direto. Planta Daninha, v.23, n.3, p.471-481, 2005.

MARTINS, D. et al. Emergência em campo de dicotiledôneas infestantes em solo coberto com palha de cana-de-açúcar. Planta Daninha, v.17, n.1, p.151-161, 1999.

MEDEIROS, D. Efeitos da palha de cana-deaçúcar (Saccharum spp.) sobre o manejo de plantas daninhas e dinâmica do banco de sementes. 2001.126 f. Dissertação (Mestrado em Agronomia) - Universidade de São Paulo, Piracicaba, 2001.

MILLS, J.A.; WITT, W.W.; BARRET, M. Effects of tillage on the efficacy and persistence of clomazone in soybean (Glycine max). Weed Science, v.37, n.4, p.217-222, 1989.

MONQUERO, P. A. et al. Eficácia de herbicidas em diferentes quantidades de palha de cana-de-açúcar no controle de euphorbia heterophylla. Planta Daninha, v.25, n.3, p.613-619, 2007.

MONQUERO, P.A. et al. Eficiência de herbicidas pré-emergentes após períodos de seca. Planta Daninha, v.26, n.1, p.185-193, 2008.

SOCIEDADE BRASILEIRA DA CIÊNCIA DAS PLANTAS DANINHAS. Procedimentos para instalação, avaliação e análise de experimentos com herbicidas. Londrina: SBCPD, 1995. $42 \mathrm{p}$.

SORENSON, B. A.; SHEA, P. J.; ROETH, F.W. Effects of tillage, application time and rate on metribuzin dissipation. Weed Research, v.31, n.5, p.333-345, 1991.
VICTORIA FILHO, R.; CHRISTOFFOLETI, P.J. Manejo de plantas daninhas e produtividade da cana. Visão Agrícola, v.3, n.1, p.32-37, 2004. 